\title{
Haematological patients admitted to icu: Differences between survivors and non-survivors
}

\author{
J Lujan Varas*, L Alcázar Sánchez-Elvira, P Villa Díaz, B Llorente Ruiz, R Molina Montero, M Rascón Risco, \\ C Arenillas Juanas, M Manso Álvarez, Y Ortiz de Zárate Ansótegui, JA Cambronero Galache \\ From ESICM LIVES 2015 \\ Berlin, Germany. 3-7 October 2015
}

\section{Intr}

Patients with haematological malignancies admitted to ICU have high mortality. Reticence of intensive care providers to admit and treat these patients is well described in literature.

\section{Objectives}

To evaluate differences between survivors and nonsurvivors and provide possible independent risk factors for ICU mortality.

\section{Methods}

Single centre observational retrospective study in a 14-bed Intensive Care Unit of a University Hospital. All haematological patients admitted between January-2009 and December-2014 were enrolled. Data acquired included: demographics characteristics, haematological diagnosis, reason of ICU admission, severity-of-illness scores (APACHE and SOFA) and intensive care therapy (mechanical ventilation (VM), extrarenal therapy depuration (ETD) and vasopressor support (VS)).

\section{Results}

We included 38 patients in the study,15(39,47\%) were survivors and 23(60,52\%) were non-survivors. Median age of $50,47 \pm 13,98$ vs $59,78 \pm 14,73(\mathrm{p}>0,05)$ and predominance of males in both groups $(60 \%$ vs $73,9 \%$, $\mathrm{p}>0,05)$, respectively. In both groups non-Hodgkin lymphoma was the most frequent haematological malignancy, 53\% and 30,4 \%, survivors and non-survivors respectively and acute respiratory failure was the most frequent reason for ICU admission(66\% and 39,1\%, respectively). Intergroup comparisons revealed statistically significant differences in APACHE $(19,73 \pm 8,05$ vs
$26,48 \pm 8,74, \mathrm{p}<0,05)$ and SOFA $(9 \pm 3,4$ vs $11,83 \pm$ $3,23, \mathrm{p}<0.05)$. During the first $24 \mathrm{~h}$ of ICU admission, $60 \%$ of the survivors patients had 2 or more organ failures, and $73,9 \%$ in non-survivors group. During evolution in ICU, survivors patients required VM and VS in $80 \%$ and $66,7 \%$, respectively. None of them needed EDT. Non-survivors required VM and VS in $91 \%$ and 95,7\% respectively, and 17,4\% needed EDT. There were no statistically significant differences in ICU support therapies between survivors and non-survivors. No independent risk factors for mortality were found by logistic regression analysis.

\section{Conclusions}

Mortality in patients with haematological malignancies remains high. There were significant differences in severityof-illness scores during the first twenty-four hours of ICU admission between survivors and non-survivors. No significant differences in intensive care therapy were found between groups during ICU hospitalization.

Published: 1 October 2015

\section{References}

1. Hampshire PA, Welch CA, McCrossan LA, Francis K, Harrison DA: Admission factors associated with hospital mortality in patients with haematological malignancy admitted to UK adult, general critical care units: a secondary analysis of ICNARC Case MIx Programme Database. Crit Care 2009, 13(4).

2. Owczuk R, Wujtewicz MA, Sawicka W, Wadrzyk A, Wujtewicz M: Patients with haematological malignancies requiring invasive mechanical ventilation: differences between survivors and non-survivors in intensive care unit. Support Care Cancer 2005, 13:332-338.

doi:10.1186/2197-425X-3-S1-A250

Cite this article as: Lujan Varas et al:: Haematological patients admitted to icu: Differences between survivors and non-survivors. Intensive Care Medicine Experimental 2015 3(Suppl 1):A250. 